\title{
Práticas emergentes de um novo paradigma de saúde: o papel da universidade
}

JAIR LÍCIO FERREIRA SANTOS e MARCIA FARIA WESTPHAL

A recente mudança de paradigma no campo da saúde

A EXPRESSÃO PRÁTICA SANITÁRIA constitui um bom exemplo daqueles nomes conhecidos e aceitos por especialistas numa certa área do conhecimento, mas quase desconhecidos do público em geral. Entre os militantes no campo da saúde, prática sanitária é, reconhecidamente, a forma pela qual a sociedade estrutura e organiza as respostas aos problemas de saúde.

No Brasil vive-se hoje um interessante e importantíssimo momento de mudanças nessa prática, encaminhadas por força da nova Constituição, precedidas e acompanhadas de intensas discussões políticas e acadêmicas. O momento não só é importante como também peculiar porque o país experimenta, de forma solitária na América Latina, a possibilidade de implementar um sistema de saúde - o SUS - compatível com as noções e os conceitos mais recentes sobre saúde e doença.

De fato, é também consenso entre profissionais da Saúde Pública de que se experimenta no mundo atual uma mudança de paradigma nas ciências da saúde. Independentemente do grau de adequação epistemológica ao se adotar os conceitos de Khun (1975) para abordar o tema, parece ser correto adotá-los pelo menos operacionalmente para melhor encaminhar a argumentação.

De maneira resumida, um paradigma segundo Khun (1975), é o conjunto de elementos culturais, conhecimentos e códigos teóricos, técnicos ou metodológicos compartilhados pelos membros de uma comunidade científica. É esse compartilhar que distingue o conhecimento científico da crença ou do senso comum. A evolução científica se dá pelo que o autor chamou de revoluções, denotando as passagens das fases de normalidade para as crises e daí para as novas teorias. 
Relevante para esta argumentação é o fato de que as respostas dadas pela sociedade aos problemas de saúde devem decorrer do conceito de saúde vigente, ou seja, do paradigma que institui esse conceito o qual, por sua vez, responde ao contexto sócio-econômico político e tecnológico vigentes. A prática sanitária, portanto, é configurada, direcionada pelo paradigma vigente e pelo contexto.

Desde há alguns anos a nossa visão da saúde passou da mera ausência da doença para a noção de bem-estar físico e mental, e daí para conceito mais amplo que inclui uma adequação de vida social. Ocorre claramente uma mudança de paradigma, inclusive com ruptura semântica entre o conceito atual de saúde e o anterior. Modifica-se a prática sanitária, passandose da antiga - curativista - para a atual - a vigilância da saúde. Retomando a exposição inicial, o Brasil vive hoje a experiência inédita da implementação, na prática, dessa revolução teórica. No que segue serão delineados historicamente os elementos dessa mudança, para mais adiante ser abordada a estratégia mais atinente à nova prática, a promoção da saúde.

\section{Saúde e doença: o paradigma flexeneriano}

No século XIX a situação da morbi-mortalidade em todo o mundo era caracterizada pela predominância de doenças infecciosas sobre as demais. No campo da saúde vivia-se ainda uma prática do ensino médico de caráter empírico, não especializado, com relativa insipiência das disciplinas afins como a Biologia e a Imunologia. O movimento sanitarista existente naquele momento na Europa e na América do Norte conseguiu interferir na situação da saúde em numerosas cidades do mundo, por meio de legislação e grandes obras de engenharia civil. Seus êxitos para diminuir a tuberculose e, sobretudo, fazer desaparecer os surtos epidêmicos de cólera, contribuíram para criar a primeira época dourada da saúde pública. Nessa época foram fundadas as primeiras instituições universitárias, indicados responsáveis por saúde em regiões administrativas e também surgiram as primeiras sociedades científicas.

Decorrente de alguns progressos no campo médico, especialmente:

- a difusão da vacinação contra a varíola depois de 1800 , resultado de um processo empírico que talvez simbolize o nascimento da imunologia;

- a identificação, por Koch, do microorganismo causador da cólera em 1883 ; 
- o desenvolvimento, por Pasteur, de sua teoria dos germes nas doenças infecciosas;

toma corpo a idéia da natureza biológica da doença, deslocando o pensamento causal em saúde do ambiente físico e social para patógenos concretos. A doença teria uma só causa, com um germe originando cada etiologia. Decorre dessa noção que saúde era a ausência da doença, isto é, a ausência de um agravo causado por um germe.

Ocorreu então um esforço acadêmico direcionado à mudança do ensino médico, que não estava preparado para responder às novas evidências e idéias. Entre os vários projetos de reformulação, o da Fundação Carnegie para o Progresso do Ensino foi triunfante, sobrepondo-se e obtendo repercussão internacional. Deu origem ao Relatório Flexener, de 1910, que veio a instituir o ideário hegemônico no campo da saúde até há alguns poucos anos (Mendes, 1985). Entre as reformas implementadas no ensino médico de então destacam-se o aumento da duração dos cursos para quatro anos, com o ensino de laboratório; a vinculação das escolas médicas às universidades e, com isso, à pesquisa e ao ensino; a ênfase na pesquisa biológica e o reforço à especialização.

Com os progressos médicos alcançados no ensino, na pesquisa e na prática foi se consolidando o paradigma, até hoje vigente. O principal elemento desse referencial é o curativismo e, entre os demais elementos, o mecanicismo (tal como acontece na mecânica clássica, uma causa atuando num corpo, sempre produz um efeito. Incorpora-se aqui a noção de unicausalidade: é uma causa, produzindo um efeito.); o biologicismo (as doenças e suas curas sempre ocorrem no nível biológico); o individualismo (o objeto das ações em saúde é um indivíduo, tratado por outro indivíduo, excluindo-se portanto dessa ação o contexto ambiental, o social e o histórico); e a especialização. O curativismo, como referido, é o elemento primordial, pois, como a saúde é a ausência da doença num indivíduo, o diagnóstico e a terapêutica ganham toda a relevância no processo. Assim, a prática sanitária passa a ser a busca da cura dos individuos que manifestaram alguma doença.

Trata-se do início da era terapêutica que, a partir da Segunda Guerra Mundial, já no século XX, foi reforçada pelo desenvolvimento moderno do Estado de bem-estar e por aumento dos recursos públicos ao setor saúde. No decorrer do processo de florescimento do curativismo, as grandes esperanças de recuperação da saúde, ausência de doença, estavam na assistência clínica, especialmente nos hospitais. 
Nesse período a saúde pública, desprestigiada, tentou resgatar o seu papel buscando se articular com os interesses econômicos e políticos das classes mais favorecidas. Assumiu o paradigma higienista, que objetivava a resolução do problema das cidades ainda não-aparelhadas para abrigar o contingente de população que para elas se deslocava. A saúde pública do início do século e as escolas de saúde pública, que em sua maioria adotaram o nome de escolas de higiene, voltaram seu interesse para os métodos sociais e ambientais objetivando a remodelação e o saneamento das cidades, e a transmissão de normas higiênicas, configurando o que tem se chamado de dicotomia prevenção/cura. Da mesma forma que o movimento sanitarista do final do século, o higienismo tinha caráter paternalista e vertical, devido ao pouco desenvolvimento ou ausência de mecanismos democráticos nas sociedades que os desenvolveram.

\section{A crise do paradigma flexeneriano}

A situação de morbi-mortalidade observada no transcorrer do século XIX foi se alterando com a diminuição da importância das doenças transmissíveis e conseqüente aumento das denominadas degenerativas, devido essencialmente às melhorias nas condições gerais de vida, mais do que aos progressos médicos mencionados (Dardet, 1994).

Por outro lado, o próprio desenvolvimento da epidemiologia e da imunologia iniciou a geração de crises para os elementos específicos do paradigma, a saber:

- crise no mecanicismo - com o desenvolvimento da noção de risco, de exposição e suscetibilidade, uma causa atuando sobre um corpo nem sempre vem a produzir o efeito esperado;

- crise no biologicismo e na unicausalidade - com a extensão das noções próprias da epidemiologia das doenças transmissíveis para as nãotransmissíveis, e com a idéia de multicausalidade; igualmente, com a conceituação de fator de risco nas doenças degenerativas, quase sempre associado ao meio físico e/ou social.

Como conseqüência mais imediata desse processo houve o deslocamento da ênfase curativa para a prevenção, resultando no que se poderia reconhecer como uma crise no curativismo, pelo menos em nível teórico. Essa crise foi mais além, pois os fatores que condicionavam a saúde não se limitavam aos elementos tradicionais do processo Saúde doença, conforme descrito pelos partidários do flexenerianismo: doença, diagnóstico, terapia, recuperação da saúde. 
O ato médico, acompanhando a crise no curativismo, perdeu o ponto hegemônico e central do paradigma, senão na prática, pelo menos no ideário dos intelectuais do setor.

\section{Um novo paradigma: a produção social da saúde}

A medicina preventiva, mesmo ampliando o espaço para a atuação do profissional de saúde, não dá conta de todo o processo saúde doença: ela pode identificar riscos, atuar sobre eles, mas não é de sua alçada a gênese desses riscos; nem o estudo de suas naturezas, mecanismos de atuação, meios para prevenir a sua existência etc. De fato, se é verdade que a medicina preventiva deu origem ao novo paradigma, não chegou a romper com o antigo (Noack, 1987; Stachtchenko \& Jenicek, 1990).

Necessário mencionar que esse encaminhamento à nova visão da saúde não se deu somente via medicina preventiva. Entre várias áreas com afinidade para a nova abordagem holística da saúde, a ampliação do conceito de educação sanitária, afastando-se da abordagem higienista, contribuiu para um dos elementos mais importantes do novo paradigma, a pomoção da saúde (Ferraz, 1998).

A nova saúde pública surge do reconhecimento de tudo o que existe ser produto da ação humana, salvo o que se poderia chamar de natureza intocada; em contraposição, a hegemonia da terapêutica, como solução para todos os males que poderiam atingir o corpo do homem. A saúde de um indivíduo, de um grupo de indivíduos, ou de uma comunidade depende também de coisas que o homem criou e faz, das interações dos grupos sociais, das políticas adotadas pelo governo, inclusive os próprios mecanismos de atenção à doença, do ensino da medicina, da enfermagem, da educação, das intervenções sobre o meio ambiente.

O informe Lalonde(1974), editado no Canadá, em 1974, questionou o papel exclusivo da medicina na resolução dos problemas de saúde, dando início a uma nova era de interesse social e político pela saúde pública. Inspirou a Conferência da Organização Mundial de Saúde (OMS) de 1977 (Saúde para todos no ano 2000). Apareceu em iniciativas nacionais como o Relatório negro sobre desigualdades em saúde (Grã-Bretanha) e na proposta Toronto saudável no ano 2000 (Canadá). Esteve ainda presente nas 38 metas de saúde para a região européia em 1985 (Jones, 1997). Ganhou mais espaço depois da Conferência de Ottawa de 1986; das declarações da OMS de Adelaide sobre Politicas públicas saudáveis em 1988; de Sundsvall sobre Ambientes favoráveis à saúde em 1991; pela Conferência de Bogotá, promovida pela Organização Pan-americana de Saúde em 1992; finalmente pela 
Conferência da OMS de Jacarta - Novos atores para uma nova era - de 1997 (Ministério da Saúde, 1996).

Vale dizer que a Constituição Federal brasileira de 1988, inspirada na Conferência Nacional de Saúde de 1986, teve seu capítulo de Saúde - que instituiu o Sistema Único de Saúde (SUS) - marcado pelo paradigma da produção social da saúde. Saúde, nesse documento inicial, foi definida como direito universal e resultante de condições de vida e trabalho, "garantida mediante políticas sociais e econômicas, que visem a redução do risco de doença e outros agravos e ao acesso universal e igualitário às ações e serviços para sua promoção, proteção e recuperação" (Brasil-Senado, 1988).

Nesse sentido, ser saudável não pode ser apenas não estar doente, no sentido tradicional. Deve significar também a possibilidade de atuar, de produzir a sua própria saúde, quer mediante cuidados tradicionalmente conhecidos, quer por ações que influenciem o seu meio - ações políticas para a redução de desigualdades, educação, cooperação intersetorial, participação da sociedade civil nas decisões que afetam sua existência - para usar uma expressão bem conhecida, o exercício da cidadania.

Entre os pré-requisitos básicos para que uma população possa ser saudável, a partir de amplas concepções de saúde e bem-estar, orientandonos pelo paradigma da história social da saúde estão: paz (contrário de violência); habitação adequada em tamanho por habitante, em condições adequadas de conforto térmico; educação pelo menos fundamental; alimentação imprescindível para o crescimento e desenvolvimento das crianças e necessária para a reposição da força de trabalho; renda decorrente da inserção no mercado de trabalho, adequada para cobrir as necessidades básicas de alimentação, vestuário e lazer; ecossistema saudável preservado e não-poluído; justiça social e eqüidade garantindo os direitos fundamentais dos cidadãos (Carta de Ottawa, 1986).

Com essa noção abrangente de saúde não ser mais a simples ausência da doença, a melhor denominação para o novo paradigma é a de produção social da saúde.

O movimento da nova saúde pública baseado nesse referencial busca métodos adequados à nossa realidade política, que tornem mais eficientes as ações sociais e ambientais por saúde e qualidade de vida. Tal aspecto pressupõe abandonar definitivamente o enfoque vertical e paternalista herdado do passado, decorrente de práticas prescritivas dos profissionais de saúde, apoiados no biologicismo e mecanicismo. Supõe, por outro lado, o desenvolvimento de novas relações com o Estado e com a sociedade civil, e 
desenvolvimento de novas habilidades dos profissionais para implementar novas práticas.

A idéia de que a saúde é produzida socialmente implica o reconhecimento de que:

- os determinantes de saúde são mediados pelo sistema social, mas também determinados pelas relações sociais, excludentes, que operam o sistema. Marmot (1996) demonstrou o quanto o controle e a autonomia dos indivíduos sobre sua própria vida são determinantes decisivos da saúde, especialmente quando comparados às ações para desestimular o hábito de fumar, por exemplo. Wilkinson (1992) demonstrou o quanto as iniqüidades, mais do que a pobreza em si, podem explicar a morbidade e mortalidade por doenças cuja prevenção é possível nas sociedades industrializadas;

- as ações que visam à resolução das distorções e desigualdades existentes nos padrões de saúde ultrapassam os limites de atuação do setor e exigem atos coordenados em várias esferas de governo (Barreto, 1996). Há portanto necessidade de ações intersetorias para a operação da nova prática sanitária;

- para que se altere realmente as condições de saúde de uma população - objetivo social relevante em todas as sociedades - tornam-se necessárias mudanças profundas em seus padrões econômicos e a intensificação de políticas sociais, que são eminentemente políticas públicas;

- há necessidade de que a sociedade civil organizada exija das autoridades governamentais a elaboração e implementação de políticas públicas saudáveis para superar o quadro mundial, e principalmente nacional, de profundas desigualdades e iniqüidades;

- é imprescindível integrar e articular diferentes saberes e práticas intra e intersetoriais, de tal forma que o novo quadro teórico e as novas práticas assumam uma nova qualidade ao serem organizadas pelo paradigma da produção social da saúde, para propor solução aos problemas existentes em um território singular - nacional, estadual e/ou local.

\section{A prática sanitária do novo paradigma: vigilância à saúde}

Muito embora os angustiantes problemas de saúde da população brasileira só possam ser resolvidos com a ação integrada de múltiplos atores sociais, de diferentes setores, mediante políticas sociais abrangentes, um 
papel de extrema importância está evidentemente destinado ao setor saúde.

O novo paradigma tem sua prática sanitária no que os autores denominam de vigilância à saúde (Mendes, 1996:243). Tal prática amplia a atuação do paradigma anterior (curativista), para dar conta da globalidade do processo saúde-doença e orienta para a reformulação das práticas assistenciais e coletivas.

Isso implica o entendimento de que saúde resulta de um conjunto de fatores políticos, econômicos, sociais, culturais que se combinam de forma particular, em cada sociedade e em conjunturas específicas, redundando em sociedades mais ou menos saudáveis.

A vigilância à saúde baseada nesse paradigma atua sobre os produtos, os processos e os insumos dos problemas, ou seja, não incide apenas nos produtos finais do processo - mortes, seqüelas, enfermidades e agravos - mas também nos assintomáticos - suspeitas, expostos, grupos de risco e necessidades sociais de saúde (Buss, 1996).

Assim, às estratégias de intervenção dessa prática correspondem diferentes tipos de controle: o dos danos de riscos e de causas, ou seja, o controle de condicionantes e determinantes. Entre as ações mais comumente desenvolvidas para atender a esses elementos citam-se:

- promoção da saúde - definida na I Conferência Internacional de Promoção da Saúde como "um processo que confere ao povo os meios para assegurar um maior controle e melhoria de sua própria saúde, não se limitando a ações de responsabilidade do setor saúde" (Carta de Ottawa, 1986), propõe a capacitação das pessoas para uma gestão mais autônoma da saúde e dos determinantes da mesma. A Organização Pan-americana da Saúde (Opas) reconhece a promoção da saúde como prioridade programática, e reitera a importância da participação da sociedade civil e da ação intersetorial, definindo-a como: "uma soma das ações da população, dos serviços de saúde, das autoridades sanitárias e de outros setores sociais dirigidas para o desenvolvimento de melhores condições de saúde geral e coletiva" (Opas/ OMS, 1993). Refere-se a ações exercidas sobre os condicionantes e determinantes e que estão dirigidas a provocar impacto favorável na qualidade de vida das populações. Além da ação intersetorial e intrasetorial, ainda se caracteriza por ações de ampliação da consciência sanitária, dos direitos e deveres, enfim de ampliação de poder de cidadania. Ações de promoção de saúde como práticas sanitárias refe- 
rem-se a práticas coletivas, voltadas para a definição de políticas, preservação e proteção do ambiente físico e social, com o apoio de informação, educação e comunicação dirigida aos profissionais e à população;

- prevenção de enfermidades e acidentes - amplia-se aqui o campo de ação da medicina preventiva no sentido do paradigma anterior, para incluir ações preventivas de caráter não-médico na prevenção às doenças. Podem ser orientadas a problemas específicos ou a grupos de problemas e a grupos de risco. Imunizações, acidentes de trabalho e de trânsito, câncer de colo e de mama, hipertensão, alcoolismo, drogas, doenças sexualmente transmissíveis, tabagismo são exemplos de problemas ou grupos de risco que podem ser beneficiados com ações de promoção ou prevenção no interior dos serviços de saúde, na prática clínica dirigida aos indivíduos, às crianças e aos adolescentes escolares, bem como à comunidade, em ações de alcance coletivo;

- atenção curativa e de reabilitação - incluídos aqui os atos curativos do paradigma anterior. Na reabilitação, o novo paradigma deve dar conta de que esta pode e deve ir mais além do que a causa física/biológica mediata. Também neste componente deve-se buscar inovações como, por exemplo, o hospital-dia e a assistência domiciliar, programa de saúde da família, práticas mais baratas e mais efetivas para a população, quando adequadamente aplicadas.

Vários programas de ensino de saúde pública vêm sendo estruturados adotando a ótica da promoção da saúde na concepção do sistema de vigilância como um todo, contribuindo na reestruturação dos programas e das práticas, no sentido do conhecimento amplo dos determinantes da saúde e na indicação de estratégias que permitam envolver outros setores governamentais e a sociedade na resolução dos problemas. Os sistemas de saúde, de acordo com tal ideário, ultrapassa a esfera do setor.

Críticas têm sido feitas aos sistemas de informação existentes, por serem excessivamente centrados nos fenômenos de morbimortalidade, em geral insuficientes para informar sobre os determinantes da saúde, prejudicando, assim, a capacidade de agir sobre os mesmos.

De fato, quando se utiliza indicadores adequados ao paradigma, elaborados para analisar o complexo de determinações de saúde expressas no nível macro e microepidemiológico, verifica-se facilmente que o trabalho de vigilância à saúde pode ser mais amplo e deve integrar saberes de práticas do setor saúde hoje confinadas em compartimentos isolados. Deve ser 
articulado com outros setores, entre eles saneamento, habitação, drenagem, educação, trânsito, turismo.

\section{Projetos estruturantes do novo paradigma: as cidades saudáveis}

Nas últimas décadas as cidades vêm ganhando significativa importância, uma vez que a maior parte da população vive e trabalha em áreas urbanas. Espera-se que no ano 2000, $80 \%$ da população total do Brasil esteja vivendo em áreas urbanas. Estas vêm se constituindo como espaço de intervenção e de mobilização em torno de projetos comuns e de interesse coletivo, que respondam à necessidade de solidariedade e cooperação social e à integração de políticas públicas urbanas.

As cidades, enquanto atores sociais, devem gerar capacidade de resposta à nova base econômica, à infra-estrutura urbana, à qualidade de vida, à integração social e à governabilidade, pois somente assim podem se tornar competitivas e dar, ao mesmo tempo, garantia de bem-estar às suas populações.

Embora, a vida nas cidades seja atraente pela promessa de maiores oportunidades de trabalho e acesso aos bens de consumo e serviços, cria também inúmeros problemas, especialmente quando a população cresce a tal ponto que as pessoas ficam expostas a uma variedade de riscos à saúde $\mathrm{e}$ não têm acesso a recursos para o atendimento de suas necessidades básicas.

Uma das conseqüências imediatas dessa realidade refere-se ao impacto sobre as condições de saúde da população. Estima-se que, neste final de século, pelo menos 600 milhões de pessoas que vivem em áreas urbanas de países em desenvolvimento estejam enfrentando condições de risco de vida e à saúde, sob condições de stress e expostos a ampla variedade de problemas de saúde, como doenças transmissíveis, desnutrição, doenças mentais e doenças respiratórias agudas e crônicas.

Os fatores e as condições que interferem nessa situação são pobreza, condições inadequadas de trabalho, iniqüidades com relação a alimentação, segurança, acesso à educação, à saúde, uso excessivo de substâncias tóxicas, poluição entre outros.

Considerando o dramático quadro da realidade urbana contemporânea, a Organização Mundial de Saúde (OMS) e suas agências regionais, como a Organização Pan-americana de Saúde (Opas), iniciaram o movimento por cidades saudáveis. As primeiras iniciativas foram realizadas na 
década de 70, no Canadá, espalhando-se depois, por intermédio da ação da OMS, por vários países da Europa, América do Norte e, mais recentemente, da América Latina. Mendes (1996:258) propõe cidade saudável como um projeto estruturante do novo paradigma.

O primeiro documento elaborado sobre o tema, de autoria dos canadenses, na década de 70, destacava questões políticas e sociais relacionadas com o desenvolvimento econômico e social. Enfatizava a necessidade da articulação de esforços dos setores públicos e privados, e de outras organizações comunitárias e voluntárias para enfrentar os diferentes problemas de saúde que vêm atingindo o meio urbano.

Os principais pressupostos do projeto por cidades saudáveis podem ser relacionados com antigas preocupações do movimento sanitário europeu do século XIX, que já reconhecia a relevância dos governos locais das cidades e das associações comunitárias como importantes agentes no equacionamento dos problemas de saúde (Westphal, 1997; 1998).

Atualmente a concepção de cidades saudáveis está ligada ao paradigma da produção social da saúde, tendo surgido como evolução natural do movimento internacional de promoção da saúde, apoiada pela OMS que, resumidamente, define a cidade saudável como aquela na qual as políticas públicas são favoráveis à saúde (Ashton et al; 1986).

O objetivo estratégico dos postulantes da proposta era motivar governos e sociedades para a melhoria das condições de vida e saúde da população urbana. Para tanto precisavam desenvolver metodologias em diversos setores de políticas sociais, implementando projetos estratégicos interinstitucionais e intersetoriais, e realizando ações em diferentes ambientes, como escola, indústria, espaços de lazer entre outros.

Um corolário desse objetivo é o de transformar as relações excludentes conciliando, ao mesmo tempo, os interesses econômicos e o de bem-estar social, condições indispensáveis para se obter saúde e desenvolvimento para as cidades, os estados e o país (Westphal, 1997).

O movimento por cidades saudáveis, que se fundamenta numa visão de saúde como qualidade de vida, focaliza também a participação popular como forma de mobilização e de democratização, valoriza o compromisso político com a eqüidade e busca mudanças na forma de gestão nos diferentes níveis de governo, sobretudo o local.

Pressupõe um processo de elaboração coletiva de determinada visão de cidade. Os projetos podem incluir saúde, e não o setor saúde, no pro- 
cesso de planejamento urbano. A complexidade dos problemas a serem tratados nessa perspectiva exige um novo enfoque de trabalho conjunto entre as várias áreas envolvidas. A transdisciplinaridade, enquanto proposta de ação das diversas disciplinas, entre elas a saúde, é que pode responder ao enfoque pretendido.

Atualmente há concordância internacional de que uma delimitação adequada para esses fins é o município, aspecto especialmente relevante para o momento histórico do Brasil, onde o setor saúde vivencia a implementação do Sistema Único de Saúde (SUS). Em função dos seus princípios de descentralização administrativa, municipalização, participação comunitária e controle social, o espaço do município para o SUS é hoje um lugar privilegiado para a implementação de estratégias de promoção de saúde e, portanto, de projetos estruturantes como Cidades/municípios saudáveis.

Já em 1986, na VIII Conferência Nacional de Saúde, realizada em Brasília, saúde foi definida como um "estado de bem-estar físico, mental e social resultante de condições de vida e trabalho" e a Constituição brasileira (Brasil, 1988), conforme já mencionado, inscreveu “... saúde como direito de todos e dever do Estado, garantido mediante políticas sociais e econômicas que visem redução da doença e outros agravos".

Esses diferentes espaços de reflexão e normalização recolocaram a saúde no Brasil em uma nova abrangência, como parte de um conjunto de condições que compõe, em determinada sociedade e momento histórico, a qualidade de vida.

$\mathrm{O}$ que ainda vem desafiando os defensores do paradigma da produção social da saúde e do projeto estruturante denominado Cidades/municípios saudáveis no Brasil, é que mesmo com várias declarações nacionais e internacionais e das leis que regulamentam o SUS (Ministério da Saúde, 1990), saúde continua a ser considerada, em cada município, como uma atividade que se refere exclusivamente à doença e, portanto, inserida ainda nos paradigmas flexeneriano, mecanicista e curativista.

Por outro lado, o que vem estimulando outros é que, em algumas experiências desenvolvidas por profissionais de saúde em cidades a partir do setor saúde, têm sido facilmente evidenciados os limites da ação setorial para a resolução dos problemas de saúde.

Para que tal proposta se estabeleça, o que precisamos hoje no nosso país é difundir a nova forma de pensar e fazer saúde, que pressupõe a existência de problemas comuns às populações que vivem num mesmo territó- 
rio; para que as administrações se abram para a inovação e se proponham a vivenciar uma nova forma de gestão municipal e governabilidade. A proposta pressupõe ainda forte protagonismo do Estado que, pela natureza dos problemas de desenvolvimento e criação de infra-estrutura a serem resolvidos, precisam ainda de muito investimento.

Os 15 municípios brasileiros que desenvolvem de forma incipiente seus projetos Cidades/municípios saudáveis (Westphal, 1998) têm tido dificuldade de assimilar o novo paradigma. Há, de modo geral, uma contradição entre a integralidade pretendida e a fragmentação imposta pela lógica das administrações municipais, centralizadas e setorizadas. Há que se ressaltar a fragilidade da experiência, assim como de outras que tentam inovar na relação Estado-sociedade civil, que sofrem permanentes descontinuidades em virtude da falta de vontade política dos governos locais e da falta de mobilização da população em torno de projetos coletivos.

Tem sido difícil o rompimento com a tradição política paternalista e clientelista, e a implantação de uma nova lógica de trabalho no aparato dos governos municipais, que se espelham nos estaduais e federal ainda setorizados e centralizados. O governo federal vem procedendo à descentralização-centralizada, uma vez que a União, cada vez mais tem centralizado as verbas e descentralizado as responsabilidades locais. O plano Real, com suas promessas de estabilização agora fortemente ameaçadas, vem juntamente com o desemprego crescente que ocorre no país, desmobilizando a população a participar de projetos coletivos (Westphal, 1998).

A Universidade, ou melhor, as escolas de saúde pública do Brasil vêm, juntamente com outras associações e conselhos, colaborando no enfrentamento de grandes desafios para a renovação dos municípios brasileiros, aprofundando as questões críticas relacionadas aos projetos Cidades/municípios saudáveis, difundindo tal prática e apoiando os municípios que desejam adotá-la. Partilhando e defendendo o novo paradigma e seus projetos estruturantes nos cursos de graduação e pós-graduação lato e estrito sensu e cursos de atualização, pretende a Universidade promover mudanças no ensino e na prática da saúde pública no Brasil.

\section{Estratégias do novo paradigma: saúde da família}

Os sistemas de saúde podem ou não ser orientados e estruturados pela atenção primária. O estudo dos sistemas de saúde tem demonstrado superioridade, quer em resultados, quer em eficiência, daqueles sistemas estruturados pela atenção em primeiro nível (Mendes, 1996:275). 
Uma estratégia de organização do sistema, coerente com a ótica da produção social da saúde, da criação de ambientes saudáveis, é a estratégia de saúde da família, a qual consiste, no primeiro nível do sistema:

- de uma atuação como verdadeiros centros de saúde operados por uma equipe de saúde da família;

- de uma delimitação territorial de abrangência com o desenvolvimento de ações focalizadas na promoção da saúde;

- numa atuação contínua, personalizada, reconhecedora da importância do relacionamento humano, estimuladora das ações intersetoriais.

Os resultados de tal estratégia têm demonstrado sua alta resolubilidade (incluindo aspectos curativos), baixos custos diretos e indiretos, com excelentes efeitos na articulação com outros setores que determinam a saúde.

Embora as faculdades de saúde pública não dêem conta da totalidade do processo de formação de profissionais e capacitação de agentes de saúde para trabalhar nesses projetos, têm dele participado juntamente com as faculdades de medicina e enfermagem, exercitando o pressuposto da transdisciplinaridade na articulação das Instituições e, conseqüentemente, dos saberes. Pólos de capacitação têm sido criados com o objetivo de preparar pessoal para os projetos e com a pretensão implícita de se contrapor ao paradigma flexeneriano, mostrando os aspectos positivos da promoção da saúde decorrente de ações concretas de saúde da família referenciadas nessa linha de pensamento.

Estratégias para os níveis secundário e terciário da atenção à saúde são abordados em outro artigo desta edição: O programa de saúde da familia em São Paulo.

\section{O papel da Universidade na nova visão da saúde}

As universidades têm acompanhado, alimentado e enriquecido as discussões dos temas aqui tratados.

Na USP, a Faculdade de Saúde Pública e os departamentos de medicina preventiva das faculdades de medicina vêm participando do movimento, assim como as áreas de saúde pública das escolas de enfermagem.

Tal participação se dá nos três níveis de atuação: na pesquisa teórica e aplicada, na participação no setor saúde dos governos federal e estadual e, em alguns casos específicos, municipais; e no ensino. 


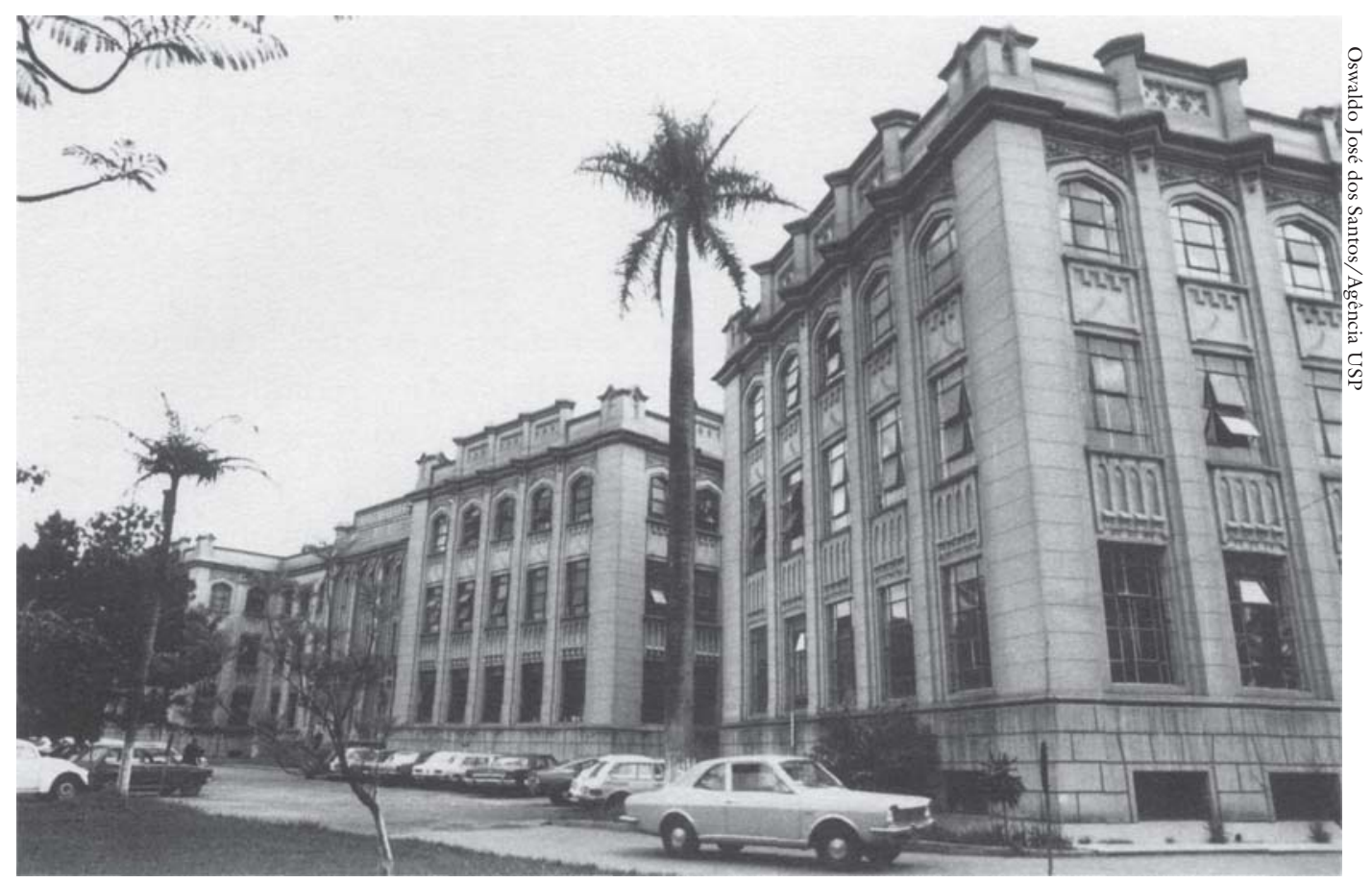

A Faculdade de Saúde Pública foi incorporada como uma das instituições da USP em 1938

A mudança do paradigma, os fundamentos epistemológicos da epidemiologia, sua extensão para além dos limites tradicionais, propostas de estruturação e reformas dos sistemas de saúde são temas que resultam em abundantes trabalhos e têm percorrido intensamente os circuitos de publicações, comunicações em congressos, mesas redondas etc.

No campo da prática, surgem novas ações sociais e novos atores: os prefeitos, as câmaras legislativas, os gestores municipais de saúde, os conselheiros municipais, as associações de usuários.

Do lado da Academia cumpre formar, atualizar e aperfeiçoar o conteúdo curricular transmitido aos profissionais que por ela passam. Necessário ainda, e isso ocorre diuturnamente, atender às solicitações que a sociedade encaminha para respostas técnicas atualizadas para os velhos e os novos problemas em saúde e ambiente.

De modo prioritário, inclusive para não fugir à sua missão primeira de produzir conhecimentos, a atividade de pesquisa deve ser orientada para equipar adequadamente o atendimento às demandas do ensino e da extensão.

Há, portanto, uma demanda por ensino, pesquisa e extensão que é, por assim dizer, adicionada à demanda tradicional. No campo da formação, por exemplo, ao mesmo tempo em que o profissional de saúde deve dar conta de tarefas tradicionais, sobretudo as de caráter técnico, necessita 
compreender o que é trabalhar em saúde hoje. Mais do que isso, deve ser equipado com o conhecimento e a habilidade para a interlocução, para se dirigir a um público mais amplo do que fazia tradicionalmente, e principalmente para incorporar em suas tarefas e aptidões o universo político que o rodeia.

Aqui talvez resida o maior desafio e a maior missão da Universidade no atual estágio da saúde brasileira: a intersetorialidade, condição básica para o progresso do sistema, traz dificuldades que lhe são inerentes e desafios que não são novos. No campo do ensino, por exemplo, devemos não apenas formar profissionais aptos ao diálogo técnico e leigo com os mais variados setores. Professores e alunos devem estar habilitados a desempenhar atividades antes não-requeridas, como a atuação política junto a grupos populacionais, institucionais e órgãos de administração pública.

Há uma demanda extensa por parte de um público até certo ponto incomum para o meio acadêmico: na Faculdade de Saúde Pública, por exemplo, num período que abrangeu o segundo semestre de 1997 e o primeiro de 1998 cerca de 400 gestores do sistema de saúde, quase todos secretários municipais, foram capacitados para o exercício de suas atividades.

Conselheiros municipais de saúde são novos personagens políticoadministrativos no cenário de implantação do SUS e constituem uma população de aproximadamente seis mil pessoas no estado de São Paulo. A Universidade lhes oferecerá igualmente capacitação por meio de um grupo de multiplicadores.

Os prefeitos dos municípios saudáveis, seus secretários e os legislativos municipais têm começado a participar de oficinas de trabalho, fóruns de discussão e discussões mais informais nos contatos possibilitados pelos projetos de extensão ou de pesquisa diagnóstica ou avaliativa relacionados com as políticas públicas.

A Universidade vem assim se revendo, se atualizando respondendo de modo positivo e eficiente às demandas sociais do setor saúde, e participando de maneira construtiva, conseqüente e solidária na implementação do SUS.

Referências bibliográficas

ASHTON, J. et al. Health cities: WHO's new public health iniciative. Health Promotion, n. 1, p. 319-324, 1986. 
BARRETO, M.L. \& CARMO, E.H. A saúde da população brasileira. In: Barros, Piola \& Vianna. Politica de saúde no Brasil: diagnósticos e perspectivas. Brasília, Ipea, Textos para discussão 401, 1996.

BRASIL. Ministério da Saúde. Lei orgânica da saúde. Brasília, Ministério da Saúde, 1996.

Promoção da saúde: Cartas de Otawa, Declaração de Adelaide, Sundsvall e Santa Fé de Bogotá. Tradução de L.E. Fonseca. Brasília, 1996.

BRASIL. Senado Federal. Constituição Federal. Brasília, Senado Federal, 1988.

BUSS, P. Saúde e qualidade de vida. In: Costa, $\mathrm{N}$ do Rosário (org.). Política de saúde e inovação institucional: uma agenda para os anos 90. Rio de Janeiro, Secretaria do Desenvolvimento Educacional/ ENSP, 1996.

CONFERENCIA INTERNACIONAL SOBRE LA PROMOCION DE LA SALUD. Carta de Ottawa para la Pomoción de la salud. Ottawa, 17 a 21 de nov., 1986.

DARDET, C.A. Que es lo novedoso en la nueva salud pública? JANO, v. 46, n. 1067, p. 39-42, jan./fev. 1994.

FERRAZ, S.T. Promoção da saúde: viagem entre dois paradígmas. RAP, Rio de Janeiro, v. 32, n. 2, p. 49-60, 1998.

JONES, L. What is health? In: Katz, J. \& Pederby, A. (eds.). Promoting health, knowledge and practice. Londres, MacMillan \& The Open University, 1997.

KUHN, T.S. A estrutura das revoluções científicas. São Paulo, Perspectiva, 1975.

MARMOT, M. The social pattern of health and disease. In: Blane, D.; Brunner, E. \& Wilkinson, R. Health and social organization: toward a health policy for the $21^{s t}$ century. London, Routlege, 1996.

MENDES, E.V. A evolução histórica da prática médica. Belo Horizonte, Fumarc, 1985.

Uma agenda para a saúde. São Paulo, Hucitec, 1996.

OPAS/OMS. Promoción de la salud en las Américas. Washington, DC, Programa provisional, tema 5.9, 1993, p. 9.

STACHTCHENCO, S. \& JENICEK, M. Conceptual differences between prevention and health promotion: research implications for community health programs. Canadian Journal of Public Health, n. 81, p. 53-55, 1990.

WESTPHAL, M.F. Cidades saudáveis: a formação de uma rede brasileira. Jornal de CONASEMS, edição especial, p. 16-19, ago. 1998.

6, n. 2, p. 9-18, 1997.

Cidades saudáveis: aspectos conceituais. Saúde e Sociedade, v. 
WILKINSON, R. Income distribution and life expectancy. British Medical Journal, n. 304, p. 165-168, 1992.

RESUMO - AS PRÁTICAS sanitárias têm se pautado sempre pelos paradigmas orientadores das ciências da saúde, que por sua vez se referenciam em parte ao contexto sócio-econômico tecnológico global e do país. O objetivo dos autores deste texto é confrontar os diferentes paradigmas que vêm orientando as práticas de saúde pública nos últimos dois séculos e definir com mais detalhes a concepção, baseada em evidências, de que saúde se produz socialmente, contrapondo-se ao paradigma flexeneriano, curativista. Pretende-se ainda apresentar novas práticas decorrentes da nova concepção que tem como eixo central a vigilância à saúde. Novos tipos de ação, como a promoção da saúde, são descritos e analisados, bem como a necessidade de integrar a nova visão às antigas práticas de prevenção $\mathrm{e}$ cura. Projetos estruturantes do novo paradigma são apresentados em linhas gerais na descrição de Cidades/municípios saudáveis e do Programa de saúde da familia. Finalizando, é analisado o papel que a Universidade e principalmente as faculdades de saúde pública vêm desempenhando diante das inovações do paradigma e das novas práticas dele decorrentes.

ABSTRACT - HEALTH PRACTICES have always been determined by the orienting paradigms of the health sciences, which in their turn refer partly to the country's global technological social economic context. The authors of this text aim at comparing the different paradigms which have been governing public health practices in the last two centuries and at defining in further details the evidencebased conception that health is a social product, opposing the Flexnerian curativistic paradigm. A further aim is to present new practices resulting from the new conception whose focal point is preventive attention to health. New types of action, such as health promotion, are described and analyzed, as well as the need to engraft the new vision on the old prevention and cure practices. The new paradigm structuring projects are outlined in the description of Towns/Healthy Counties and of the Family Health Program. Concluding, the role the university and mainly the public health colleges have been playing vis-a-vis the innovations of the paradigm and the practices it originates is analyzed.

Jair Lício Ferreira Santos é professor titular do Departamento de Epidemiologia da Faculdade de Saúde Pública da Universidade de São Paulo, da qual atualmente é diretor

Marcia Faria Westphal é professora titular do Departamento de Prática de Saúde Pública, eixo temático de promoção de saúde da Faculdade de Saúde Pública da Universidade de São Paulo, da qual atualmente é vice-diretora. 